\title{
Probation: what next and who decides?
}

Sam Ainslie considers recent attempts to increase probation's profile after unification and asks what these conflicting portrayals of probation mean for the future of the service. 
I have previously argued that there is a need to address the dissonance and instrumentalism within probation policy and practice documentation, to provide a clear mandate for desistance-supportive practice and greater alignment with the values of practitioners (Ainslie, 2021). The unification of probation services in England and Wales at the end of June 2021 has inevitably heralded a raft of new documentation and communication from key policy personnel seeking to engage with the 16,000 probation staff across England and Wales and the general public; crucially, this includes the 220,000 individuals subject to probation intervention. With this in mind, I've returned to the work of Weiss and Wozner (2002) to explore which 'model' of probation has been communicated during the unification process and to consider 'what next for probation?' and 'who decides?'.

Based on a review of probation literature, Weiss and Wozner (2002) outlined 10 alternative models for probation services based on key variables including underlying perceptions of the causes of crime and the goal of punishment; the aims of probation; the key audience for intervention; the strategies used and the role of probation practitioners. The models sit within two main categories where probation is either perceived as an alternative to punishment (with little emphasis placed on control, surveillance or enforcement) or as an alternative form of punishment (where emphasis is placed on responsibility for offending behaviour and minimal attention is paid to support and care

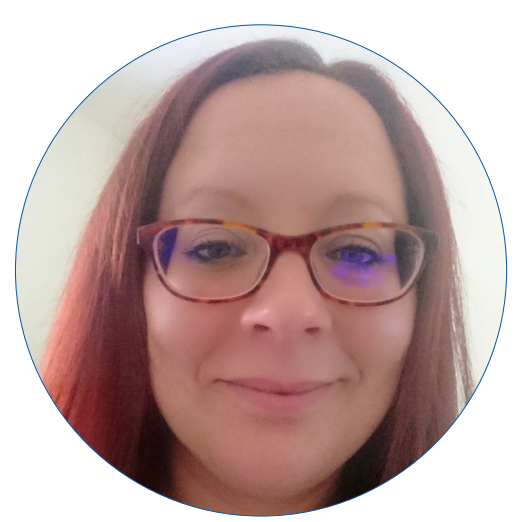

Sam Ainslie

Senior Lecturer in Criminal Justice Sheffield Hallam University

functions). Whilst acknowledging the considerable debates that exist about probation practice, Weiss and Wozner argued that the 10 models can be used to define probation and assist with 'locating and identifying changes in approach' (2002: 85). What follows is a reflection on the 'models' that are suggested in recent probation communication and documentation.

In a video deployed through Twitter in the week of unification, the MOJ present probation practitioners as 'crime fighters' who use technology (polygraph tests and sobriety tags to name just two) to monitor 'dangerous offenders' and 'protect the public' from serious harm. 
This vision of probation characterised by enforcement and surveillance, and where the public are identified as the 'client of protection' resembles Weiss and Wozner's 'supervision' model (2002: 101) where the aim of probation becomes imprisonment and incapacitation is the prevailing philosophy of punishment. At best, it suggests an approach aligned to the 'retribution' model where the aim of probation is punishment in the community with a singular focus on public protection in the absence of supporting serviceuser change.

This positioning of probation is arguably at odds with the messaging from HMPPS in recent months. The Target Operating Model for Probation (HMPPS, 2021) declares that the purpose of probation is to 'Assess, Protect and Change' and aims to protect 'against further offences' whilst 'addressing the harm caused by the original offence' (2019: 6). So here we see again the 'retribution model' with the positioning of the public as the client in need of protection and an effort to present probation as a 'robust and effective' alternative to custodial sentences which can be delivered through resource brokerage. Here we also see evidence of Weiss and Wozner's 'case management' model where the primary role of practitioners is to assess need and broker interventions. In a positive development there is a commitment to using non-stigmatising language, although there is clear dissonance between this and the MOJ communication used to promote the unified service to the public.

Further dissonance is evident with the Target Operating Model's commitment to using unification to 'reinforce' probation ethics (2021: 6). Whilst these are not outlined in the document, a footnote provides the link to the Probation Institute Code of Ethics. Listed in primary position is the belief in the capacity of service-users to achieve a change for the better; a belief consistently communicated by practitioners in the course of probation research despite organisational turmoil and change (Ainslie, 2021; Deering, 2011). This belief is closely followed by charging probation with responsibility for the promotion of social justice and social inclusion, and therefore an alignment with Weiss and Wozner's 'reintegration model'. Here probation practitioners are tasked with working with service-users and the community (both positioned as clients for change) to achieve 'mutual tolerance and positive relationships' (2002:91) with the aim of community integration and the delivery of rehabilitation. So, whilst the Probation Institute position does not align completely with Weiss and Wozner's 'radical socialist model', the commitment to social reform, community change and empowerment of service users suggests some overlap.

Finally, the Chief Inspector of Probation provides yet another vision for probation as deliverer of 'effective programmes' that seek to 'prevent re-offending' and 'properly support and inform victims' (Russell, 2021). The focus here on probation work as a vehicle for crime reduction and public protection, but with a foregrounding of commitment to victims is suggestive of Weiss and Wozner's 'justice model' intertwined with the assessment and brokerage aspects of the 'case management' model that has prevailed in England and Wales in the last 20 years. Here it would seem that the vision of probation continues to be influenced by an efficiency credo that is characterised by pragmatism and efficiency (Rutherford, 1994). 


\section{Implications}

Somewhat ironically then, at a time of unification there would appear to be continued dissonance in terms of the stated aims of probation and the underlying values and principles that guide probation work. This dissonance is nothing new to probation practitioners or those who research probation work. It is however disappointing given the potential impact on staff morale and occupational identity already weakened by Transforming Rehabilitation. Arguably this dissonance does little to aid public perception of probation and instead (if we consider the MOJ portrayal) has the potential to strengthen the structural barriers experienced by people on probation in the form of further discrimination and 'othering'.

Finally, as an academic with responsibility for teaching PQiP students, I find myself considering the impact of this dissonance on recruitment and training under the unified model of probation. When applying to become a Probation Officer, which 'model' of probation do trainees believe they will be delivering and how equipped are they to navigate the potential conflict between their values and the stated organisational aims? As Weiss and Wozner rightly conclude, 'most aspects of probation are the subject of considerable debate' (2002:86), and it looks like this debate is set to continue despite the opportunity provided by unification to provide a more coherent vision of probation for the future.

\section{References}

Ainslie, S. (2021) 'Seeing and Believing: Observing desistance focused practice and enduring values in the National Probation Service', Probation Journal, 68 (2): 146-165. https://doi. org/10.1177\%2F02645505211005031

Deering, J. (2011) Probation practice and the new penology, Farnham: Ashgate.

HMPPS (2021) The Target Operating Model for Probation services in England and Wales, available at https://assets.publishing.service.gov.uk/government/ uploads/system/uploads/attachment data/ file/959745/HMPPS - The Target_Operating_Model for the Future of Probation Services in England Wales - English - 09-02-2021.pdf

Ministry of Justice (2021) How a probation officer fights crime available at https://twitter.com/MoJGovUK/ status $/ 1409753599471726597 ? \mathrm{~s}=20$

Probation Institute (2020) Code of Ethics available at https://www.probation-institute.org/code-of-ethics

Russell, J (2021) A new dawn for probation? available at https://www.justiceinspectorates.gov.uk/ hmiprobation/2021/07/01-july-2021/

Rutherford, A. (1994) Criminal justice and the pursuit of decency, Winchester: Waterside Press.

Weiss, I and Wozner, Y (2002) 'Ten models for probation supervision compared across eight dimensions', Journal of Offender Rehabilitation, 34 (3): 85-105. https://doi.org/10.1300/J076v34n03 06 